\title{
GETTING ENTREPRENEURSHIP EDUCATION OUT OF THE CLASSROOM AND INTO STUDENTS' HEADS
}

\author{
Martin J. Bliemel \\ mbliemel@unsw.edu.au \\ School of Management \\ Australian School of Business \\ UNSW Australia \\ Kensington, NSW 2052 \\ AUSTRALIA \\ Tel: +61 (0)2 93855671
}

*** Pre-proof manuscript. Please cite as: ***

Bliemel, M. (2014) "Getting Entrepreneurship Education Out of the Classroom and Into Students' Heads" Entrepreneurship Research Journal, 4(2), p. 237260 (dx.doi.org/10.1515/erj-2013-0053)

*************************************** 


\section{Introduction}

The debate on whether or not entrepreneurship can be taught has continued for many years (e.g., see Henry, Hill and Leitch 2005 for a review), and appears to have been concluded with a "yes .. but." In general, reviews of entrepreneurial education (hereafter EE) indicate that "yes" it can indeed be taught (see Hindle 2007; Franco, Haase and Lautenschläger 2010; Wadhwa 2010). The "but" part says that the design of EE programs is highly context dependent, and its impact is also highly contingent on several factors, including when EE is taught, by whom, and how (as also argued by Jones and Matlay 2011). Rather than lament the heterogeneity of EE programs and the difficulty in evaluating and comparing them, this study appeals to those who aim to celebrate the diversity of EE programs, and learn from improved detail regarding their origins, motivations, and methods, and of the people involved.

This paper is a case study of EE at the University of New South Wales (UNSW) that encompasses not just the contents and methods of the EE program, but also reveals the history and purpose of the program, the institutional context, and the qualifications of the educator. By providing such a detailed and comprehensive overview, this study responds to recent critical reviews of the $\mathrm{EE}$ literature that call for more detail. For example, Fayolle's reflective review identifies that "Studies into who entrepreneurship educators are and what they really do in their interventions are sorely missing. Whether educators and instructors in EE need to have prior entrepreneurial expertise is also an issue that has not been examined in the literature" (Fayolle 2013, 695). To this he adds that "few articles go beyond the description of contents and methods to consider the rationale leading to effective didactical designs" (ibid.). Likewise, a recent special issue in the Journal of Small Business Management on EE decries that "many of the linkages between entrepreneurship in the classroom and entrepreneurship in the "real world" remain largely unknown" (Vanevenhoven and Liguiri 2013). In contrast, this paper attempts to provide the full picture of EE; not just paying lip service to its importance, but revealing the efforts involved in establishing and maintaining EE programs, and providing operational detail that the above reviews call for. 


\section{Literature review}

2.1 When is appropriate to teach entrepreneurship?

A dilemma exists in EE regarding when entrepreneurship can or should be taught. In his reflections on two Kauffmann studies about EE (Wadhwa et al. 2009a, 2009b), Wadhwa (2010) concludes that:

“The key is to provide education at 'teachable moments' - when the entrepreneur is thinking about starting a venture or ready to scale it. What entrepreneurs need isn't the type of abstract course they teach at business schools, but practical, relevant knowledge."

The dilemma resides in different stories being told by the entrepreneurs versus students in the surveys. On the one hand, data from entrepreneurs reveals that university is the perfect time for EE (Wadhwa 2009), and it is inferred that "these individuals [25-34 years of age] are likely to have had some time to develop their skills and knowledge through higher education and work experience" (Xavier et al. 2013, 22-29). On the other hand, data from students reveals that "just a small fraction of students is disposed to step into selfemployment, and the vast majority has not yet made the decision" (Franco, Haase and Lautenschläger 2010, 260). As a result, this teachable moment may pass many students by. Meanwhile, teachable moments also exist much earlier; as evidenced by extra-curricular entrepreneurship programs as early as middle- or high-school (Bliemel, Glave and Logue 2010; Athayde 2012), and by the consideration to include Economics and Business in the grade 5-10 national curriculum in Australia (ACARA 2013).

\subsection{Who is qualified to teach entrepreneurship?}

Who should teach entrepreneurship also presents an ongoing debate. Certainly at the university level, at least for coursework students, it is argued that the lecturer's experience is particularly important due to the increasing complexity to ground management theories in real experience (Bennis and O'Toole 2005). Those more critical of academics posit that academics are "too often uncomfortable dealing with multidisciplinary issues in the classroom. They are ill at ease subjectively analysing multifaceted questions [..], or examining cases that require judgment based on wisdom and experience" (ibid., 101). The counterargument is that the very nature of universities and science is to be critical of subjective accounts, and that universities are not vocational institutions 
wherein instructors apprentice students into a practice (Hindle 2007). One solution, is, of course, the 'pracademic' who has practical experience and academic credentials at their disposal to help ground or embed theory into complex and uncertain contexts such as entrepreneurship (Penaluna, Penaluna and Jones 2012).

\subsection{Who should own EE programs?}

Perhaps the single largest debate in EE is the operational question of how it can be taught and what the curriculum design might look like. The bigger question here is which faculty determines the design of the EE program, and for whose students? The classic question about the design and ownership of the program is whether EE belongs in business schools, or if the business school is the "wrong building" (Hindle 2007) because business schools generally teach how to work in someone else's business (Aronsson 2004; Rideout Gray 2013). Contributing to the debate about design and ownership, is the lack of consensus regarding which students EE programs should cater to (Jones and Matlay 2011; Jones, Matlay and Maritz 2012). While there is no clear solution to this debate, the present case study presents the design of an inter-faculty program, that is owned by the business school, administered by a community centre within that school, but draws on courses and caters to students of all faculties.

\subsection{Does EE even belong in the university?}

University may be the right place to learn about entrepreneurship as a phenomenon, but not necessarily to learn how to do it and experience what it's like to become and entrepreneur. Indeed, EE programs frequently change content to keep up with the reality of how rapidly entrepreneurship practices change, and often sacrifice academic content for current content and current practices (Penaluna, Penaluna and Jones 2012). The theory-practice tension is not unlike medical school, wherein it is important to learn about the latest medical findings, as well as to practice the latest techniques.

Just to be clear, teaching theory and critical thinking in the university classroom is important (cf. Wadhwa 2010), but so is making sure students are a little more prepared for the practicing world upon completion of their coursework. This calls for a balanced approach. While Haase and Lautenschläger $(2011,145)$ declare that "EE should desist from simply teaching knowledge on business creation and rather focus on experiencing entrepreneurship," (emphasis added) 
their declaration remains ambiguous; while they call for a change in focus, they implicitly leave the option for multiple foci.

The panacea for university-based EE lies in experiential learning opportunities, which ironically often means learning off-campus and in the 'real world'. Some argue that experiential learning is not only critical to EE, but that it is also what makes EE unique. For example, Haase and Lautenschläger (2011, 147) even state that "experience-based soft skills related to entrepreneurship are rather difficult to impart or develop, but they are much more important and render EE unique" (emphasis added). Reviews of EE in Sweden also emphasize an action-based approach (e.g., Rasmussen and Sørheim 2006) in which students take ownership of their ideas, instead of discussing cases of others' ideas. Unfortunately, operational details on the experiential learning components remain sparse (Vanevenhoven and Liguiri 2013).

The importance of interacting with the 'real world' is clearly visible in most reviews of EE, including Wadhwa's (2010) conclusion that that "it is probably education, exposure to entrepreneurship, and networks that lead these people to pursue the entrepreneurial path," or Haase and Lautenschläger's (2010) long list of experiential learning components. Even journalists who have probably never read a single article on EE have an opinion on what should be included in EE, including internships (Featherstone 2013, especially including the comments following the article) and selling (Silberman 2013). The latter is also presented by Birch as one of "three skills that an entrepreneur needs to know and master" (Aronsson 2004, 290), followed by leadership or managing people and then creating a new product or service.

In response to the cacophony of components that people believe should be part of EE, this article provides a single case study of how multiple components interact into an integrated curriculum design. I am not implying that this is the best solution for any university; only that it is the EE program that has evolved at UNSW. The present paper builds on the above debates, while also acknowledging two additional important factors: (i) that the popularization of the lone hero entrepreneur is contra how entrepreneurship occurs (Dimov 2007), and that an emphasis on interdisciplinary teams is more appropriate (Eisenhardt and Schoonhoven 1990), and (ii) that a significant number of entrepreneurial opportunities are a serendipitous or unplanned by-product of doing something else 
(Dew 2009; Bliemel 2013). The second point supports the emerging popularity of the Lean Startup method (Ries 2011), which runs contra EE's historical emphasis on business plans.

With these debates and factors in mind, the remaining sections of this paper are structured as follows. In the background section, I first provide some context to my professional background to contextualize the question of who is qualified to teach entrepreneurship. I then review the academic context in which EE has evolved at UNSW, including multiple faculties. This is followed a section on the recently revised inter-faculty Diploma in Innovation Management at UNSW, with emphasis on its first core course, "MGMT2010 Innovation and Entrepreneurship, Principles and Practice." The course is featured here because of the portfolio of experiential learning opportunities it contains. Some indicators of performance and outcomes of the course are then discussed. Lastly, I summarize some limitations and opportunities for extensions, followed by the conclusion section.

\section{Background}

\subsection{Personal context}

Given the aforementioned debate of who is qualified to teach entrepreneurship, I disclose my professional background as it relates to EE. During and after my undergraduate in mechanical engineering, I worked in the capacity of factory maintenance, research and development (R\&D), and consulting engineering. I then pursued an MBA with specialization in new ventures and knowledge management, including writing a business plan for a proposed business incubator. Thereafter, I moved to Vancouver, Canada to start a business consulting company (i.e., a virtual business incubator), specializing in assisting technology entrepreneurs with market research, financial modeling, business plan development, and investor pitches. During that time, I was also a mentor with the New Ventures Business Competition (Canada's largest), and presentation room manager with the Angel Forum (Canada's oldest angel investor network's semiannual event). Through these experiences, I was struck by the slow pace at which entrepreneurs adapted to feedback from multiple stakeholders. When pushed outside of their comfort zone, many preferred to go back to what they knew how to do best: adding another feature to the technology. 
As I transitioned into my $\mathrm{PhD}$ research, I considered the challenges of business incubation, and the emerging evidence that networks and programs were more important than subsidized office space (e.g., Colombo and Delmastro 2002). I now have the pleasure to teach approximately 200 students per year who selfselect into my courses, are quite engaged, and act on stakeholder feedback within days or weeks. Although only some of the students are in STEM (Science, Technology, Engineering, and Math) programs, all students understand the concept technology as a scalable platform for business; especially once 'technology' is generalized to include “devices, artifacts, [business] processes, tools, methods, and materials that can be applied to industrial and commercial purposes" (Byers, Dorf and Nelson 2011, 19).

\subsection{University context:}

For EE programs, the institutional context is proposed as a significant factor (Franco, Haase and Lautenschläger 2010). University can be seen as a 'safe' environment in which to cultivate students' entrepreneurial intentions. It is a time and place they are expected to learn, and a failed assignment or poor grades do not need to stand in the way of learning.

As with just about any university, UNSW faces the challenge of providing a transition into an entrepreneurial ecosystem beyond the classroom. In addition to taking EE programs that are based on coursework assignments, students may be socialized into entrepreneurship via complementary initiatives. In particular, within the faculty of business, a community center called the Centre for Innovation \& Entrepreneurship (CIE) was established in 2007 and funded by donations from industry with which it could afford one full-time staff. I became the Director of the CIE in 2010, shortly before the Academic Board approved the revised version of the Diploma in Innovation Management, and I maintained this role until the end of 2012.

At least until the end of 2012, four of the major initiatives of the CIE included (i) running the annual business plan competition, (ii) semi-annual networking events for entrepreneurs and alumni, (iii) bi-weekly on-campus brainstorming lunches in collaboration with the technology transfer office, NewSouth Innovations (NSi), and (iv) administration of the Diploma in Innovation Management (detailed below). The CIE also became a clearinghouse 
for news and events related to innovation and entrepreneurship, often simply redirecting others to the next most appropriate person or announcement.

In 2011, NSi had a leadership change including a shift from focussing on the intellectual property (IP) to focussing on the inventors, innovators, and entrepreneurs. This shift involved giving IP away to get it in the hands of businesses, under the banner of "Easy Access IP" (Ross 2011). The general philosophy of the Easy Access IP program is to avoid focussing on short-term licensing fees, and that businesses and society should benefit more readily from tax payer funded research. This philosophical shift is underpinned by an assumption that some of these rewards by businesses and entrepreneurs may later voluntarily flow back to the university as significant donations. Shortly after the leadership change, NSi broadened their pool of inventors beyond researchintensive staff, to include any staff or students who may wish to (i) commercialize their own ideas, or (ii) commercialize some of the Easy Access IP. The move included recruiting a Student Enterprise Manager whose role it is to help launch student-based ventures by facilitating access to IP, legal support, market research reports and other resources previously reserved for researchers.

In addition to the $\mathrm{CIE}$ and $\mathrm{NSi}$, other organizations across campus collaborated with CIE and NSi on more of an ad hoc basis, including:

- UniSeed, a seed stage venture fund operated by the Universities of Melbourne, Queensland and UNSW;

- Australia Technology Park Innovations (ATPi), a technology incubator coowned by UNSW, University of Sydney (USyd), University of Technology Sydney (UTS), and Australian National University (ANU);

- Venture Space, a co-working space within the faculty of Computer Science and Engineering (CSE) specializing in CSE students and recent graduates; and

- the UNSW Entrepreneurship Society, a student society founded to stimulate more awareness and learning about entrepreneurship.

The increasingly complex set of organizations and stakeholders across the university, meant that there were increasing opportunities and logistical challenges in leveraging their synergies. 


\section{The Diploma in Innovation Management}

\subsection{Program history}

The Diploma in Innovation Management (hereafter the Diploma), was first launched in 2001 by Dr. Wallace Bridge in the Faculty of Science, and administered within the Entrepreneurs in Science (EIS) unit which Wallace directed. Its curriculum was designed to be completed concurrently with an undergraduate degree in Science, but could be completed as an extension to the degree. While it was initially exclusive to science students, engineering students were eventually permitted into the program on a case by case basis. Despite winning an award from the Australian National Teaching Council for the Diploma in 2008 , the program was at risk because the EIS unit was winding down.

Around this time, I joined UNSW and was assigned the task of completely revising the Diploma including moving its ownership and administration to the business school, and (more importantly) making it available to undergraduate students of all faculties. This process alone took approximately 12 months and 100 consultation meetings with stakeholders of each of the eight faculties, including lecturers of core and elective courses to be included in the Diploma, Deans, Associate Deans Education, Associate Deans Undergraduate and other levels of administration. Each person's opinion had to be considered and incorporated into the revision in order to get approval at Education Committees and Standing Committees in multiple faculties, through to approval by the Academic Board.

Overall, this program revision was a process that is not to be underestimated by anyone wishing to pursue a similar inter-faculty program at a comparable university. I do not envy colleagues at two other nearby universities who are attempting to design a similar Diploma. One university is challenged by their current institutional context in which each faculty has independently launched their own courses on business plans, innovation or entrepreneurship. In this context, each faculty is not interested in coordinating, aggregating and packaging the courses into a Diploma program owned by another faculty, because courses and tuition might disappear, along with the marketing value to prospective students and employers. 


\subsection{Program design}

The revised Diploma curriculum includes core courses that focus on the fundamentals of entrepreneurship (MGMT2010), leadership, and communication, as well as an option of two capstone business plan courses (one in Engineering and one in Science). Prior to taking the capstone course, students would have to complete two electives, including the option to complete a work placement course that was exclusive to the program. Each course already existed and was part of the initial diploma program (e.g., the leadership, communication and work placement courses) or part of other degree programs.

Over two dozen elective courses were offered across almost all faculties, and were selected based on discussion with and approval by each course's lecturer or program authority. Students taking the course as part of the Diploma would only marginally add to the enrolments in those courses. At the time, students were not permitted to count any course towards their degree and the diploma, simultaneously. In a more recent minor revision to the Diploma, the total number of courses required increased by two, however students were permitted to count two Diploma courses towards their 'general education' (Gen-Ed) requirement in their main degree program. During later this minor revision, the work placement course also became a core course, further cementing the experiential learning aspect of the Diploma. Interestingly, to this date, no business plan capstone is offered within the business school; only the faculties of science and engineering offer such a capstone into the Diploma.

\section{Innovation and Entrepreneurship, Principles and Practice}

\subsection{Course history}

This course was launched as part of Professor Ben Oviatt's yearlong visit to UNSW and offered as a general elective. For the first year I taught the course, I only made minor modifications to the course design while focusing on revisions to the Diploma. Much to Ben's credit, much of the course's design has remained the same, including guest speakers and live pitches to judges. I initially advertised the course with paper flyers in each faculty's student administration office, and later by having it included in the university's online course handbook in the 'official' list of courses eligible for Gen-Ed credit. Despite this list, any course outside a students' home faculty could be eligible for Gen-Ed credits if the student meets the course's minimum requirements (if any). Nonetheless, many 
students relied on this 'official' list to select their Gen-Ed courses. Feedback from the students showed that the flyers had little effect, that the listing as a Gen-Ed course had a minor effect, and that most students either found out about the course by word-of-mouth or by searching for entrepreneurship keywords in the online course handbook.

The course attracts a modest number of students (so far maximally 140 in one semester) who self-select into the course as a Gen-Ed option (for nonbusiness majors), free elective (for business majors), or via the optional Diploma. This means that enrolments are lower than at other universities in which entrepreneurship is a core course in a larger program (e.g., as with some Bachelor of Commerce programs). However, the self-selection also means that the average student is highly engaged. Every second semester, a parallel course is offered at the postgraduate level (MGMT5607 Entrepreneurship and New Venture Management). Both courses were initially blended into one classroom. The courses were later separated as it appeared more beneficial to undergraduates to not assume the postgraduate students on their teams would automatically lead the team assignments, and postgraduate students benefited from smaller class sizes with more in depth discussion and more advanced course materials.

\subsection{Course design}

The course is designed such that students learn how to develop their business idea while pitching it in a variety of formats. The course content and sequence was initially based on Kawasaki's (2004) "The Art of the Start" with additional content provided for each section (more on that below). The course text was recently changed to Ries' (2011) “The Lean Startup." Ries' book focuses on the iterative process of building a prototype, testing it in the market, and learning from the results (i.e., successes and failures) to develop the next version; a process which he calls the Build-Measure-Learn feedback loop. This feedback loop is also captured in the Act-Learn-Fix cycle in the textbook for the postgraduate students by Byers, Dorf and Nelson (2011). All three books, and recent trends in the startup scene, acknowledge that writing a business plan is a great way to explicate the design of a new venture, but that the development of a business design is best done by pitching and pivoting (i.e., changing part of the business design while keeping other aspects the same) as often as required until a convincing product and business design emerges. 
Additional content includes effectuation theory (Sarasvathy 2001), financial modeling and valuations (course materials developed by me and made available via CIE's website), mentoring guidelines (also on CIE's website [i] and inspired by Steve Blank's guidelines), statistics on business starts and failures (e.g., Fisher and Reuber 2010), overviews of angel and VC landscapes (e.g., Ruffolo, Sauvageau and Nardi 2008; Ramadani 2009), diffusion of innovation (Bass 1969; Rogers 2003), global trade network evolution (e.g., Serrano, Boguñá and Vespignani 2007), the lean canvas (Maurya 2012), the strategy canvas (Kim and Mauborgne 2005), Product-Customer-Matrix (Boardman, Shapiro and Vining 2004), Gartner's Hype Cycle [ii], disruptive innovation (Bower and Christensen 1995), open innovation (Chesbrough 2003), serendipity (Dew 2009; Bliemel 2013), and more.

\subsection{Assignments}

The majority of each student's marks (55\%) are based on team marks, and the rest $(45 \%)$ determined by individual performance. In earlier cohorts, freeriding became evident, and subsequent trials of peer-assessment tools (e.g., WebPA [iii]) provided an efficient mechanism to reduce freeriding. The peer-assessments provided multiple benefits in that students learned to set and gauge expectations within their teams, learned to articulate each team member's contributions, and the tool not only penalized free-riders or absentees who skipped the assessment, but adequately rewarded others who put in more than their fair share of effort. Student built up their soft skills (e.g., as advocated by Haase and Lautenschläger 2011) by setting expectations within their team, managing those expectations on an ongoing basis, and then providing feedback with the WebPA system.

While the initial course design included a policy that no one shall disclose any teams' ideas outside of the classroom out of precaution that someone might 'steal' the idea, I completely reversed this viewpoint. In my version of the course, the emphasis is less on perceived novelty and more on execution and validation, as also emphasized by examples from the popular press (e.g., Hoffman 2010). Indeed, students are encouraged to imitate ideas that were proven elsewhere in order to focus on fewer unique points of distinction in the business, and to avoid reinventing too many wheels. 


\subsubsection{Team assignments}

As their first assignment, students are given 3 weeks to form teams (ideally 4-6 members) with the requirement that each team include someone with (i) a technical major (STEM or Design), (ii) a business or economics major, (iii) an international student, and (iv) someone fluent in English. At the same time, they must find a mentor for their course project; an increasingly popular experiential learning method (Lefebvre and Redien-Collot 2013). One semester I experimented with randomly assigning teams and prescribing mentors to test whether students could spend less time organizing their teams and more time working on their project. The experiment worked in regards to spending more time on their project, but failed in the sense that students did not learn to network within the cohort to form teams. In the experiment, they were also given one less incentive to network outside the cohort to find their own mentor, and often took the mentor for granted and failed to engage them. Thus, I reverted to assisting teams in learning to network without handing them their mentoring relationships.

The second team assignment is a combination of a live pitch and a 3minute YouTube pitch, due around the mid-point of the course. The live pitch is done at the beginning of the week in front of a live panel of judges, usually including actual entrepreneurs, investors, and technology-transfer experts. Mentors are also invited to attend the live pitches. Each live pitch is 3 minutes, followed by 3-5 minutes of questions and answers, depending on the number of teams per cohort. Judges fill out scoring sheets and comment on the overall performance of the cohort. Students are also given scoring sheets. While the scores are not part of the grades, they give the students a clear signal about the quality of their pitch. The real value in the live pitches is in the question and answers. I also immediately scan all the scoring sheets to a pdf and upload them to the course website so all teams see all (anonymous) feedback by judges and students. This way, students also begin to learn to give feedback on pitches.

The second part of the second team assignment involves creating a 3minute pitch and uploading it to YouTube by the end of the same week of the live pitch. This delay allows for feedback from the live pitch to be incorporated into the video pitch. Students must then share the URL on the course website (lately, an educational group page within Facebook; thus enabling further peer commentary), and email it to myself and their teams' mentor. The video also 
often becomes part of the student's online portfolio upon graduation. I then grade the video pitches and have the luxury of being able to pause and rewind at will.

Towards the beginning of the final week of the course, the students once again do live pitches to entrepreneurs, potential investors, technology-transfer experts and invited mentors. The difference between the first and second pitches is that the judges' scores for the second pitches are combined with my own to form their grades, whereas the first pitches are for feedback only. By the end of the final week, teams are expected to incorporate feedback from the live pitches into their final 4-page business description (i.e., executive summary), which is then emailed directly to me. This final 4-page assignment is the only team assignment that does not include an experiential learning component involving non-students. However, it may later be used with potential investors should the students actually decide to pursue the idea. Aside from the practicality of marking shorter assignments, the final assignment is deliberately kept short to force students to learn to convincingly communicate their business idea in succinct form, while being prepared to provide greater detail, should a boardroom presentation follow.

\subsubsection{Individual assignments}

The practicality of teaching larger courses predisposes individual assessments towards multiple choice quizzes. This course also makes use of two multiple choice quizzes, scheduled near the mid-point and the end of the course. One of my revisions to the multiple choice quizzes was asking fewer multiple choice questions, and adding short answer questions under each remaining multiple choice question. These short answer questions either asked for an explanation of their selection from the multiple choice component, or asked for explanation of a concept to the multiple choice question. This revision promotes further development of the student's ability to explain and pitch their ideas. For the lecturer, this combination helped evaluate how often students were simply guessing the right answer without an explanation, or had the correct explanation at a conceptual or abstract level, but failed to identify the correct multiple choice answer. The quizzes themselves did not include an experiential component. However, the quizzes include questions relating to guest speakers, through which the students received "indirect experience" (Shepherd 2004), thus incorporating previous experiential learning moments. 
Recent changes to the individual grades include providing extra marks if students pitch their idea at a competition and win (more points for first place than other places). These pitching events help students transition out of the classroom and publicly demonstrate many of the graduate attributes they are expected to develop via the course. Based on the uptake of the challenge to pitch in public, I have begun offering students to write a 2-page reflective summary of the event, including describing how the event relates to course materials and how the event had an impact on their (personal or teams') venture idea. This reflective summary is graded and used for a quiz exemption. For the last year, networking events also qualify for quiz exemptions, since networking essentially involves several elevator pitches, listening to feedback and evaluating other participants' pitches. In the undergraduate class approximately $20 \%$ of the students completed such quiz exemptions two semesters ago, increasing to just over $50 \%$ in the semester ending November 2013, and $100 \%$ of the postgraduate students opted for quiz exemptions.

\subsection{Experiential Learning Opportunities}

Using the above course design and assignments, students are provided three levels of experiential learning opportunities: indirect, virtual, and direct (see also Shepherd, 2004 for his lists of indirect and direct experiences). Firstly, they receive indirect experience via the guest speakers in the course, and from engaging with their team mentors. Guest talks usually involve open questions and answers, and provide greater engagement than video clips I can embed in some lectures (e.g., Stanford's Entrepreneurship Corner videos are a great resource [iv]). Indirect experience from the mentors is facilitated by recommending students that they interview their mentors about the mentors' business (see also Scherer et al. 1989). Since adopting the course, I have halved the number of guest speakers and replaced those sessions with workshops, at no detriment to the feedback regarding speakers. I made the change because many students thought they were hearing the same story multiple times from each guest speaker, not (yet) picking up on the nuances of their stories, and starting to skip guest speaker session later in the course. From their perspective, the workshops only add to the experience. Evidence of indirect learning is captured in individual quizzes and reflected in the quality of team assignments.

Secondly, they also receive virtual experience, which is experience that is essentially what it would be like to be an entrepreneur, but still within the 
artificial confines of the classroom. This 'safe' environment reduces students' fear of failure and even encourages them to experiment and learn through each iteration's success or failure (or 'flearn' according to local accelerator operators). Networking to form teams and finding a mentor fall into this category. Mentors are often either from previous work experiences, family friends or via LinkedIn. The initial premise of the mentorship is to assist the students with their course project, and hold them accountable for regular progress and iterations of their business idea(s).

Additional virtual experience is facilitated via bi-weekly workshops (alternating with guest speaker weeks) which include activities many entrepreneurs would do, but also remain within the confines of the classroom. For instance, the first workshop is about creativity and networking, and involves students coming up with a business idea and pitch based on three random words, followed by walking around the room, networking to other students and finetuning their (often quite entertaining) very short pitch. This workshop teaches them to step outside their comfort zone to meet (as yet) perfect strangers, and to become more efficient about summarizing their business idea, as might occur when swapping business cards in a hurry. In the most recent semester, guests from industry helped facilitate workshops, adding immense richness to the discussion. This included having a member of the local angel network participate in a workshop in which students role-played as seed fund managers and decided how to place their investments. In another workshop, the boss of a former student brought in a briefing for a platform patent they recently attained, around which students designed diverse business ideas.

Another virtual experience is via their YouTube pitches and use of social media in the course, in which students learn to communicate their pitch and to give feedback on each others' pitches in a professional manner. While the social media is still generally within the confines of the (virtual) classroom, it is directly analogous to what occurs in practice, as for example as part of the application process to business accelerators. Evidence of virtual learning is revealed in their efforts and discussions during the workshops, as well as in the quality of team assignments.

Lastly, students also gain direct experience by pitching to actual investors and by networking outside the classroom in a variety of settings. In order to test 
the hypotheses on which their business idea is built, they are encouraged to contact actual potential customers, suppliers and partners. Such external stakeholders are usually friendly to the prospect of helping students learn. As the students begin to take their project more seriously, they may downplay their student status when approaching such stakeholders, and contact them as if the business were real. The sensation of what it is like to actually be an entrepreneur is reinforced during live pitches to the judges in the classroom, who judge student teams as if they are real ventures. Some of the judges have seen hundreds or thousands of pitches as part of their occupation, and personal feedback from judges indicates that they actually find it difficult to think any differently than as if judging a real pitch by a real entrepreneur. Feedback from students includes that they find some of the judges' feedback quite critical, but ultimately immensely rewarding.

Perhaps the most 'real' direct experience students have is when they participate in optional off-campus networking and pitching events that are open to the public. Students may initially participate in these events for quiz exemptions, bonus marks and experience. Interestingly, upon winning, students are hardly concerned about claiming bonus marks for wins, and find the external validation about their potential to create and develop new ventures quite rewarding. In order to use participation in such an event as a quiz exemption, students much submit a reflective summary of the event before the quiz, which provides ample evidence of learning.

The reflective summaries often indicate that students initially feel ill prepared to network, but quickly get over it, and realize that 'real' entrepreneurs are equally nervous and sometimes even less prepared for such live interactions. For example, one student wrote:

"Most of the pitchers had obviously not followed the course [..] and were a bit confused or not direct enough in their pitches, talking too much about their product and not enough about their business model for example, or even not about their needs. I sometimes did not understand the idea of the business." (student, used with permission) 
The degree to which students underestimate their own confidence and capabilities is occasionally witnessed in their comments about unexpectedly winning pitch competitions. For example, one team recently participated in an industry pitch competition against 20 other teams, only to find out they were the only student-based venture. The reflective summaries of the team members also show that they treated it simply as a chance to practice their pitch, that they were in it entirely for the experience, and that none of them actually expected to win. For example, one student in the winning team wrote:

"We won! I could not believe it and I had this kind of thoughts in myself "No this is a joke and I will wake up" and "It cannot be serious, we are the less worthy of the competition." [..] I felt a bit confused with our win: I did not take it seriously; I was just interested in the experience it could bring me (and have not been disappointed on that point). But after the announcement of the results I did not know anymore what to do with the prizes: a return ticket to the Silicon Valley, an exhibition stall at the CeBIT event at the end of the month, some consulting hours with PwC... And all was so close in terms of deadlines! The day after, we met up together with my team. They all told me that they were ready to start something real and to try making money with this idea." (student, used with permission)

For context, this team's idea was based on a patent held by Intellectual Ventures (Myhrvold 2010). At the beginning of the course, a former student who now works for Intellectual Ventures contacted me out of the blue with an offer to give current students a look at some patents she believed that students could design a business around. Upon winning the aforementioned competition, the students enlisted the support of NSi to formalize the access to the patent. Thankfully, NSi has a positive working relationship with Intellectual Ventures, as shown in a more than half-serious private comment by NSi's CEO to the Portfolio Head at Intellectual Ventures who was then handling the appropriate patent: "We've invented a new model for tech transfer here. [..] I told you student enterprise was a big thing!" (Cullen 2013, private message, used with permission). 


\section{Program and course evaluations}

At the program level, the performance of the revised Diploma remains difficult to assess because the program revision is still too recent for students to have graduated from the revised Diploma. That said there is a vibrant alumni group on LinkedIn of graduates from the previous incarnation of the Diploma. Judging by their career paths, including R\&D consulting, technology transfer, business incubation, and entrepreneurs, the graduates appear to be building directly on the Diploma.

At the level of the core course that I teach, feedback indicates that the program design is well received and increases interest and commitment towards becoming an entrepreneur. Even quite superficially, I ask for a show of hands at the beginning and end of the lecture series with the "Reversed-Stairs" model (Uebelacker 2005) to see what proportion of students are (i) aware of entrepreneurship as an alternative, (ii) interested in entrepreneurship, (iii) willing to be an entrepreneur, (iv) planning to be an entrepreneur, or (v) are an entrepreneur. On average, students advance at least one step closer to becoming an entrepreneur, with 10-20\% moving two or more steps, and a handful per cohort becoming entrepreneurs. Verbal in-class feedback of students who shifted multiple steps indicates they were initially quite intimidated by the prospects of being an entrepreneur until they realized that no special or super-human skills are required, and that they do not give up their social lives as much as they transform them (entirely consistent with Hite and Hesterly 2001). Upon popular request by several students who have completed the course, I have also set up a LinkedIn network for them to keep in touch with each other and share updates about their entrepreneurial pursuits.

Formal teaching evaluations show that students consistently rate the course higher than the faculty average; out of seven evaluations, rating the overall course from 0 to 100 , the course was consistently rated 4-10 points higher than the faculty average, with an average of 5.6 points higher. Qualitative comments from the students include specific comments of appreciation of the guest speakers, live pitches, interdisciplinary work, and other experiential learning components, especially the quiz exemptions.

Beyond the feedback within the classroom or formal course evaluations, I regularly receive encouraging unsolicited feedback from recent graduates of the 
course by email, in person, and even occasional unsolicited recommendations via LinkedIn. In 2011, my revisions to the Diploma and the course were a core component of a nomination by the Dean towards the "Award for the Best Entrepreneurial Educator of the Year," a National award conferred by the Business/Higher Education Round Table, sponsored by Engineers Australia. In 2012, the course design was cause to receive a faculty-level teaching award for the "Outstanding Technology-Enabled Teaching Innovation Award," out of approximately 300 eligible faculty members.

Another excellent metric for the course resides in the performance of the students. A selection of recent outcomes of students in the course includes:

Winning competitions:

- 2013 TiE Sydney $1^{\text {st }}$ place: https://sydney.tie.org/article/51/compakt-wins-tiepitching-comp-close-contest

- 2011 TiE Sydney $1^{\text {st }}$ and $3^{\text {rd }}$ place: https://sydney.tie.org/article/51/youngentrepreneur-wins-clash-titans-pitching-contest

- 2013 Microsoft Imagine Cup Australia $1^{\text {st }}$ place: http://www.microsoft.com/australia/presspass/post/Microsoft-Imagine-Cupwinners-aim-to-ease-hunger-and-poverty-in-Australia

- And subsequently the 2013 Microsoft Imagine Cup Worldwide Finals 3rd place in the World Citizenship category: http://www.imaginecup.com/ic13/team/confufishroyale\#?fbid=ZezLxam6I4A

- 2013 Multiple international design awards: http://www.smh.com.au/national/health/portable-oxygen-cylinder-a-breath-offresh-air-for-children-with-respiratory-conditions-20131110-2x9ve.html

- 2012 NSW Pearcy Awards $1^{\text {st }}$ place: http://www.nsinnovations.com.au/blog/2012/10/unsw-student-start-winspitching-contest-nsw-pearcy-awards

- 2011 Idea2Product $2^{\text {nd }}$ place: http://www.asb.unsw.edu.au/newsevents/mediaroom/media/2011/november/P ages/pluvision_i2p_sweden.aspx

Ventures launched or products commercialized

- 2013: Forcite Helmet: http://www.prlog.org/12101139-australian-forcite-lawenforcement-and-emergency-services-helmet-will-save-lives.html (recipient of a privately disclosed significant amount of angel capital) 
- 2012 Zenogen: http://www.sydneyangels.net.au/zenogen-clinches-angelfunding (recipient of a $\$ 435,000$ in angel funding; IP licensed from UNSW via the Easy Access IP program)

- 2012 One Cent Flights: http://www.brw.com.au/p/techgadgets/one_cent_flights_zeroes_in_on_its_COpb4MQ84Vg5ifLODDiyJN

And working with some of the world's most well-known startups in Silicon Valley:

- 2013 Zynga: http://sashmackinnon.com/what-its-like-to-work-with-markpincus

\section{Implications for practice}

This study summarizes the history, design and evolution of an inter-faculty EE program at UNSW. The design is specific to the institutional context of UNSW, and the availability of complementary resources and people within the university. The design is also lucky enough to readily leverage a vibrant local entrepreneurial ecosystem. The design of the EE program provided here may provide a guideline for other institutions who wish to develop interfaculty EE programs, provided it can be tailored to their specific context.

\section{Limitations and opportunities for extensions:}

With every iteration and revision of the course and program design, we must not only acknowledge successes, but also limitations. While the unsolicited positive feedback and news of recent graduates is encouraging, this feedback is acquired unsystematically and obviously biased towards successful outcomes. Maintaining contact with students upon completion of the course or upon graduation remains a challenge for any university or lecturer, but may be facilitated via social media (e.g., facebook groups may be more persistent than eLearning platforms, and LinkedIn groups are increasingly common, too). I am currently considering merging the facebook groups such that former students can observe and comment on contributions (e.g. YouTube pitches) of current students. As one former student noted, "I think consolidating the Facebook cohorts is a great idea, I'm sure that past cohorts would be very interested to give feedback and contribute. It can also be a great way that past and present students can connect with each other in one active place" (past student, used with permission). 
An extension to a post-graduate version of the Diploma has been explored with some members of the administration, and there have been occasional requests by potential students. However, momentum to develop such a program requires more effort than is currently available. For example, one challenge is in gaining support from other faculties to promote a program that is 'owned' by the business school. As commented by one key stakeholder for the Diploma, "nobody would voluntarily promote a "competitor" product (even if it is from the same university)" (confidential identity 2013). Such tensions exist in many (if not all) universities, and may result in essentially the same course being reinvented and offered separately by each faculty, as is the case in another nearby university. Additionally, an operational challenge with a post-graduate offering would be to design experiential learning components in a meaningful way. Potential students who have inquired about a postgraduate Diploma include professionals who already have significant experience in industry. Thus, their existing experience may limit the need for experiential learning.

Lastly, there is an as yet hypothetical possibility to extend the course into a massive open online course (MOOC) to reach much larger numbers of students. While MOOCs are currently receiving a lot of media attention, the hype seems unjustified if completion rates are often much less than $10 \%$ (Webb, 2013) and if courses require hiring "teaching assistants and tutors to create emotional buy-in and attachment with students" (Harris 2013). There is an obvious tension in the idea of creating a MOOC with its emphasis on online learning versus the experiential emphasis of EE. Given the encouraging feedback from getting students out of the classroom seen above, perhaps a hybrid MOOC is required to get students out of the online interface, aka a massive open hybrid online course (MOHOC) in which students document their experiences outside of the confines of the MOOC using reflective summaries.

Similarly, there is a lot of interest in the "flipped classroom" (Bergmann and Sams 2012), wherein students process lecture materials in their own time (online), and do their 'homework' and workshops in the scheduled classroom time. While the flipped classroom emphasizes reorganizing the interaction between the teacher, students and course materials, interaction with industry remains largely absent from the discussion. The course design provided here is currently being redesigned to be delivered in more of a flipped classroom 
technique, while maintaining or even increasing the level of interaction with entrepreneurs, investors, mentors and other people in industry.

\section{Conclusion}

This article has provided a case study that reveals how EE may involve experiential learning components that gradually push students out of the classroom, out of their comfort zone, and into an exciting world of entrepreneurship. The curriculum design introduces three levels of experiential learning opportunities: indirect experiences via guest speakers and mentors, virtual experiences via pitches in the classroom to real investors, and (optional) direct experiences via pitching their ideas at industry networking events and pitch competitions. This gradual approach eases students into the process of acting and thinking like real entrepreneurs. As evidenced in the reflective summaries of students who have won pitch competitions, this gradual approach may at first be taken for granted in the pursuit for experience, but later appreciated when they realize the real potential of their work.

\section{References}

Aronsson, Magnus. 2004. "Education Matters-But Does Entrepreneurship Education? An Interview With David Birch." Academy of Management Learning \& Education no. 3 (3):289-292.

Athayde, Rosemary. 2012. "The Impact of Enterprise Education on Attitudes to Enterprise in Young People: An Evaluation Study." Education + Training no. 54 (8/9):709-726.

Australian Curriculum, Assessment and Reporting Authority "Draft Years 5-10 Australian Curriculum: Economics and Business Information Sheet." Last modified May, 2013, Accessed February 22, 2013. http://www.acara.edu.au/curriculum_1/learning_areas/humanities_and_so cial_sciences/economics_and_business.html

Bass, Frank. 1969. "A New Product Growth Model for Consumer Durables." Management Sciences no. 15 (5):215-227.

Bennis, Warren G, and James O'Toole. 2005. "How Business Schools Lost Their Way." Harvard Business Review no. 83 (5):96-104.

Bergmann, Jonathan, and Aaron Sams. 2012. Flip Your Classroom: Talk To Every Student In Every Class Every Day. International Society for Technology in Education.

Bliemel, Martin J. "On the Resource Foundations and Triggers of Lucky Events". Paper presented at the Australian Centre for Entrepreneurship Research Exchange, Brisbane, QLD, February 6-8, 2013. 
Bliemel, Martin J, Linda Glave, and Greg Logue. 2010 "Learning the art of Entrepreneurship.” Business/Higher Education Round Table News no. 29: 12-14

Boardman, Anthony E, Daniel M Shapiro, and Aidan R Vining. 2004. "A Framework for Comprehensive Strategic Analysis." Journal of Strategic Management Education no. 1 (2):1-36.

Bower, Joseph L., and Clayton M. Christensen. 1995. "Disruptive Technologies: Catching the Wave." Harvard Business Review no. 73 (1):43-53.

Byers, Thomas H, Richard C Dorf, and Andrew J Nelson. 2011. Technology Ventures: From Idea to Enterprise. 3rd ed: McGraw Hill.

Chesbrough, Henry. 2003. Open Innovation: The New Imperative for Creating and Profiting From Technology. Harvard Business School Press.

Colombo, Massimo G, and Marco Delmastro. 2002. "How Effective are Technology Incubators? Evidence From Italy.” Research Policy no. 31 (7):1103-1122.

Dew, Nicholas. 2009. "Serendipity in Entrepreneurship." Organization Studies no. 30 (7):735-753.

Dimov, Dimo. 2007. "Beyond the Single-Person, Single-Insight Attribution in Understanding Entrepreneurial Opportunities.” Entrepreneurship Theory and Practice no. 31 (5):713-731.

Eisenhardt, Kathleen M, and C laudia B Schoonhoven. 1990. "Organizational Growth: Linking Founding Team, Strategy, Environment, and Growth Among U.S. Semiconductor Ventures, 1978-1988." Administrative Science Quarterly no. 35 (3):504-529.

Fayolle, Alain. 2013. "Personal views on the future of entrepreneurship education." Entrepreneurship \& Regional Development no. 25 (7-8):692701.

Featherstone, Tony. "Why Aren't More Students Working for Start-ups?” Sydney Morning Herald, April 23, 2013, accessed April 23, 2013, http://www.smh.com.au/small-business/managing/blogs/the-venture/whyarent-more-students-working-for-startups-20130423-2ibf7.html

Fisher, Eileen, and Rebecca Reuber. 2010. "The state of entrepreneurship in Canada". Ottawa, On: Industry Canada, accessed October 1, 2011, http://www.ic.gc.ca/eic/site/061.nsf/eng/h_rd02468.html

Franco, Mário, Heiko Haase, and Arndt Lautenschläger. 2010. "Students" Entrepreneurial Intentions: An Inter-regional Comparison." Education + Training no. 52 (4):260-275.

Haase, Heiko, and Arndt Lautenschläger. 2011. "The 'Teachability Dilemma' of Entrepreneurship.” International Entrepreneurship and Management Journal no. 7 (2):145-162. 
Harris, Aaron. "Where Robots Fail: Why Education Can't Just be Digital" Accessed June 20, 2013. http://venturebeat.com/2013/05/17/where-robotsfail-why-education-cant-just-be-digital

Henry, Colette, Frances Hill, and Claire Leitch. 2005. "Entrepreneurship Education and Training: Can Entrepreneurship be Taught? Part II." Education + Training no. 47 (3):158-169.

Hindle, Kevin. 2007. "Teaching Entrepreneurship at University: From the Wrong Building to the Right Philosophy", In Handbook of Research in Entrepreneurship Education, edited by Alain Fayolle. Vol. 1: A General Perspective. Cheltenham, UK: Edward Elgar.

Hite, Julie M and William Hesterly. 2001. "The Evolution of Firm Networks: From Emergence to Early Growth of the Firm." Strategic Management Journal no. 22 (3):275-286.

Hoffmann, Claire. "The Battle for Facebook." Rolling Stone, September 15, 2010, accessed October 2, 2010: http://www.rollingstone.com/culture/news/thebattle-for-facebook-20100915

Jones, Colin, and Harry Matlay. 2011. "Understanding the Heterogeneity of Entrepreneurship Education: Going Beyond Gartner." Education + Training no. 53 (8/9):692-703.

Jones, Colin, Harry Matlay, and Alex Maritz. 2012. "Enterprise Education: For all, or Just Some?" Education + Training no. 54 (8):813-824.

Kawasaki, Guy. 2004. The Art of the Start: The Time-Tested, Battle-Hardened Guide for Anyone Starting Anything. New York, NY: Portfolio.

Kim, W. Chan., and Renée Mauborgne. 2005. "Blue Ocean Strategy: From Theory to Practice." California Management Review no. 47 (3):105-121.

Lefebvre, Miruna R, and Renaud Redien-Collot. 2013. " "How to Do Things with Words": The Discursive Dimension of Experiential Learning in Entrepreneurial Mentoring Dyads." Journal of Small Business Management no. 51 (3):370-393.

Maurya, Ash. 2012. Running Lean: Iterate from Plan A to a Plan That Works: O'Reilly Media.

Myhrvold, Nathan. 2010. "Funding Eureka!" Harvard Business Review no. 88 (3):40-50.

Penaluna, Kathryn, Andy Penaluna, and Colin Jones. 2012. "The Context of Enterprise Education: Insights into Current Practices." Industry and Higher Education no. 26 (3):163-175.

Ramadani, Veland. 2009. "Business Angels: Who They Really are." Strategic Change no. 18 (7-8):249-258.

Rasmussen, Einar A, and Roger Sørheim. 2006. "Action-based Entrepreneurship Education.” Technovation no. 26 (2):185-194. 
Rideout, Elaine C, and Denis O Gray. 2013. "Does Entrepreneurship Education Really Work? A Review and Methodological Critique of the Empirical Literature on the Effects of University-Based Entrepreneurship Education." Journal of Small Business Management no. 51 (3):329-351.

Ries, Eric. 2011. The Lean Startup: How Today's Entrepreneurs Use Continuous Innovation to Create Radically Successful Businesses. New York: Crown Business.

Rogers, Everett. Diffusion of Innovations (5th ed.). New York: Free Press, 2003.

Ross, John. "Free to a good home: UNSW shares its IP." The Australian, November 9, 2011, accessed November 9, 2011: http://www.theaustralian.com.au/higher-education/in-depth/free-to-agood-home-unsw-shares-its-ip/story-fnaswzb5-1226189239714

Ruffolo, John, François Sauvageau, and Robert Nardi. "Global Trends in Venture Capital 2007 Survey.” Deloitte, January 31, 2008, accessed10 July 2009: http://www.slideshare.net/bwatson/global-trends-in-venture-capital-2007survey

Sarasvathy, Saras D. 2001. "Causation and Effectuation: Toward a Theoretical Shift From Economic Inevitability to Entrepreneurial Contingency." Academy of Management Review no. 26 (2):243-263.

Scherer, Robert F, Janet S Adams, Susan S Carley, and Frank A Wiebe. 1989. "Role Model Performance Effects on Development of Entrepreneurial Career Preference.” Entrepreneurship: Theory \& Practice no. 13 (3):5371.

Serrano, M Ángeles, Marián Boguñá, and Alessandro Vespignani. 2007. "Patterns of Dominant Flows in the World Trade Web." Journal of Economic Interaction and Coordination no. 2 (2):111-124.

Shepherd, Dean A. 2004. "Educating Entrepreneurship Students about Emotion and Learning from Failure." Academy of Management Learning \& Education no. 3 (3):274-287.

Silberman, Astrid. "Should Selling be Taught at University?" Australian Anthill, January 18, 2013, accessed April 23, 2013: http://anthillonline.com/dowe-really-need-to-be-taught-selling-at-university/

Uebelacker, Stefan. 2005. Gründungsausbildung: Entrepreneurship Education an Deutschen Hochschulen und ihre Raumrelevanten Strukturen, Inhalte und Effekte. Wiesbaden, Germany: Deutscher Universitätsverlag.

Vanevenhoven, Jeff, and Eric Liguori. 2013. "The Impact of Entrepreneurship Education: Introducing the Entrepreneurship Education Project." Journal of Small Business Management no. 51 (3):315-328.

Wadhwa, Vivek, Krisztina Holly, Raj Aggarwal, and Alex Salkever. 2009a. "Anatomy of an Entrepreneur: Family Background and Motivation." 
SSRN eLibrary. Accessed December 10, 2010.

http://ssrn.com/abstract=1431263

Wadhwa, Vivek, Krisztina Holly, Raj Aggarwal, and Alex Salkever. 2009b. "Anatomy of an Entrepreneur: Making of a Successful Entrepreneur." SSRN eLibrary. Accessed December 10, 2010. http://ssrn.com/abstract=1507384

Wadhwa, Vivek. "Can Entrepreneurs Be Made?" TechCrunch, February 27, 2010, accessed February 27, 2010: http://techcrunch.com/2010/02/27/canentrepreneurs-be-made/

Webb, Jenn. "Visualization of the Week: MOOC Completion Rates." O'Reilly Strata, March 27, 2013, accessed May 10, 2013: http://strata.oreilly.com/2013/03/visualization-of-the-week-mooccompletion-rates.html

Xavier, Siri R, Donna J Kelley, Jacqui Kew, Michael D Herrington, and Arne Vorderwülbecke. 2013. The Global Entrepreneurship Monitor: 2012 Global Report. Accessed May 10, 2013: http://www.gemconsortium.org/docs/2645/gem-2012-global-report

Referenced online resources:

[i] http://www.cie.unsw.edu.au $\rightarrow$ Resources

[ii] http://www.gartner.com/technology/research/methodologies/hype-cycle.jsp

[iii] http://webpaproject.lboro.ac.uk/

[iv] http://ecorner.stanford.edu/ 